\title{
O DESENVOLVIMENTO DAS POLÍTICAS PÚBLICAS CIENTÍFICAS NO BRASIL: BREVE RELATO E COMENTÁRIOS SOBRE SUAS POTENCIALIDADES
}

\author{
CARINA PASCOTTO GARROTI \\ Faculdades Metropolitanas Unidas, Programa de Pós-graduação em Jornalismo Cultural \\ <carinagarroti@ig.com.br>
}

DOI: 10.21439/conexoes.v10i3.811

\begin{abstract}
Resumo. Este trabalho reflete sobre a importância das políticas públicas científicas, sob uma perspectiva do histórico brasileiro. Faz primeiro um estudo sobre o que se entende por políticas públicas e o ciclo de vida que geralmente possuem (identificação do problema; conformação de agenda; formulação; implementação; avaliação; extinção). Na sequência, há um breve relato de como as políticas públicas científicas foram ganhando espaço na agenda pública brasileira ao longo dos anos, a partir de meados dos anos 80 até os dias atuais e por último, as transformações que essas políticas podem ocasionar na sociedade de uma maneira geral, considerando a importância da Ciência, Tecnologia e Inovação (CT\&I) na atualidade. O trabalho utilizou-se de revisão bibliográfica, baseando-se nos trabalhos de Dias (2012), Secchi (2012); é descritivo, monográfico e de caráter qualitativo. Os resultados demonstram que as políticas públicas científicas brasileiras foram desenvolvidas ao longo das décadas de forma incipiente, dentro das possibilidades orçamentárias, estando por muitas vezes em segundo plano devido a problemas políticos e/ou econômicos que precisavam de medidas e investimentos urgentes. Portanto, a política brasileira científica foi desenvolvida com atraso em comparação a outros países e mantém-se até hoje longe da porcentagem de investimento ideal para resultar em desenvolvimento satisfatório científico e dentro das necessidades do país. Portanto há ainda muito a investir e a crescer dentro das políticas de C\&T no Brasil.
\end{abstract}

Palavras-chaves: Políticas públicas científicas. Ciência. Tecnologia. Inovação. Brasil.

\begin{abstract}
This paper reflects on the importance of scientific policies, from the perspective of the Brazilian history. Do first a study on what is meant by public policies and the cycle of life that usually have (problem identification, agenda conformation, formulation, implementation, evaluation, extinction). Following, there is a brief account of how the scientific public policies were gaining ground in Brazilian public agenda over the years, from the mid-80s to the present day and finally, the changes that scientific policies may result in society in general, considering the importance of Science, Technology and Innovation (STI) today. The work we used a literature review, descriptive, monographic, qualitative in nature and adopted the single case study methodology. The results demonstrate that the Brazilian scientific policies have been developed over the decades of incipient form, within the budgetary possibilities, with many times the background due to political and / or economic problems that need urgent measures and investments. Therefore, the scientific Brazilian policy was developed late compared to other countries and remains to this day far from ideal investment percentage to result in satisfactory scientific development and within the country's needs. So there is much to invest and grow within the S\&T policies in Brazil.
\end{abstract}

Keywords: Scientific public policy. Science. Technology. Innovation. Brazil. 


\section{INTRODUÇÃO}

As políticas públicas são responsáveis por grandes mudanças sociais. São a resposta das lideranças governamentais para problemas de ordem econômica, política e de desenvolvimento social. A sociedade, juntamente com diversos grupos de poder, participa ativamente ou passivamente da elaboração dessas políticas e dependem também, em grande parte, do grau de engajamento da população. Uma das áreas de grande importância para a sociedade é a Ciência e Tecnologia (C\&T), descrita neste artigo.

Por meio de revisão bibliográfica, este trabalho descreve resumidamente, portanto, alguns tópicos relevantes da área, que são: a) o que se entende por política pública; b) o ciclo de vida de uma política pública, desde a sua criação até a extinção; c) breve relato de como as políticas públicas de ciência ganharam espaço na agenda pública brasileira desde meados dos anos 80 , quando foi criado o Ministério de Ciência e Tecnologia até hoje (estes três primeiros itens baseando-se principalmente nos trabalhos de Dias (2012) e Secchi (2012)); e d) as transformações que as políticas públicas científicas podem oferecer. Trata-se de pesquisa monográfica, descritiva e de caráter qualitativo. Os objetivos da pesquisa são, portanto, conceituar brevemente as políticas públicas; realizar um breve histórico de como as políticas públicas de ciência se desenvolveram no Brasil a partir da década de 80; e discutir a relevância das políticas públicas científicas para o desenvolvimento do país.

Como explica Demo (2001), a pesquisa qualitativa também formaliza a preocupação de "conferir à análise qualitativa o contexto social e histórico que não pode ser visto apenas como enfeite eventual, mas como constitutivo de sua gênese" (DEMO, 2001, p. 48). Santaella (2001) complementa que "a pesquisa qualitativa acabou por desenvolver autonomia própria, podendo se referir a todas as pesquisas que privilegiam a interpretação dos dados, em lugar de sua mensuração" (SANTAELLA. 2001, p. 144).

\section{A DEFINIÇÃO DAS POLÍTICAS PÚBLICAS}

Primeiramente é conveniente abordar o que entendemos por política. Dias (2012) conceitua a palavra de três maneiras:

Um particular significado associado à palavra "política" está ligado à noção de política como norma jurídica que tem como objetivo a alteração ou a manutenção de um determinado aspecto de natureza social, econômica, cultural, etc. Outro significado atrelado à palavra "política" remete aos interesses (particulares ou de grupos), fatores culturais, padrões de comportamento político e ati- tude dos atores, presentes, sobretudo, na dimensão processual da política. Por fim, vale ressaltar ainda que a palavra "política" está também associada à idéia de ambiente político-institucional no qual os processos políticos ocorrem. Em inglês, esse conceito está vinculado à palavra polity. (DIAS 2012 p. 43)

Das três conceituações, é importante destacar as construções "alteração ou manutenção de um determinado aspecto"; "interesses (particulares ou de grupos"; e "ambiente político-institucional". Dessas três ideias, é possível entender o processo da política como manipulação de resultados por meio dos grupos de poder considerando interesses e ambientes políticos. Não somente no sentido pejorativo, mas em ambos os casos quando a política intervém positivamente e/ou negativamente.

Também é interessante verificar o que se entende por Estado. O mesmo autor colabora com algumas opções, a depender das teorias básicas envolvidas. Se considerarmos que a política pública é uma ação estatal, como é conhecida atualmente, a teoria que melhor define a estrutura vivenciada no Brasil, democraticamente, é a contratualista:

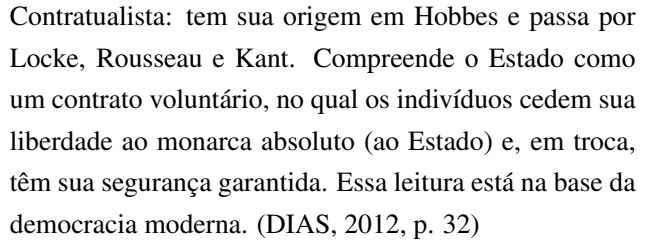

$\mathrm{O}$ autor ainda garante que a maioria dos estudos das políticas públicas parte da ideia de que o surgimento do Estado se deu por meio de consenso social, ou seja, o povo deu plenos poderes para que o Estado tomasse medidas para o bem comum, como quisesse, dentro dos princípios da democracia.

Há ainda um segundo conceito inserido nessa temática do Estado capitalista, que legitima e naturaliza a propriedade privada. E neste ínterim entra a desigualdade social, e a visão marxista do Estado. Assim, dentro dos preceitos da elegibilidade, de representação política, o povo dá plenos poderes para que os governantes administrem o país da forma que considerem mais pertinente. Por isso, "frequentemente se compreende a política pública como uma ação ou conjunto de ações por meio das quais o Estado interfere na realidade" (DIAS. 2012, p. 41).

Secchi (2012) oferece outra conceituação: "políticas públicas tratam do conteúdo concreto e do conteúdo simbólico de decisões políticas e do processo de construção e atuação dessas decisões" (SECCHI, 2012, p. 1). Complementa que 
uma política pública é uma diretriz elaborada para enfrentar um problema público. (...); uma política pública possui dois elementos fundamentais: intencionalidade pública e resposta a um problema público; em outras palavras, a razão para o estabelecimento de uma política pública é o tratamento ou a resolução de um problema entendido como coletivamente relevante. (SECCHI 2012 p. 2)

Logo, uma política pública nasce quando a comunidade e os governantes entendem tratar-se de um problema comum, de interesse público. A ciência há muito tempo tem sido entendida dessa forma, portanto. Secchi (2012) diz que a abordagem estadista admite que atores não estatais até têm influência no processo de elaboração de políticas públicas, mas não confere a eles o privilégio de estabelecer e liderar um processo de política pública. Já acadêmicos da vertente multicêntrica admitem tal privilégio a atores não estatais.

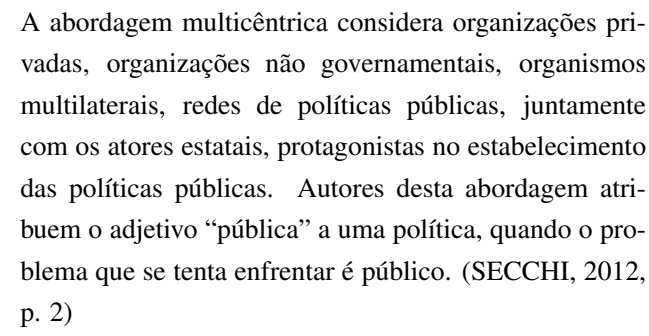

Neste trabalho optou-se por essa última abordagem como norte do entendimento por políticas públicas, porque a teoria multicêntrica leva em consideração a participação da mídia e da comunidade acadêmica, que no Brasil, no início dos anos 2000, exigiu medidas quanto à popularização da ciência por meio das conferências de C\&T (2 $/ 2001,3^{\mathrm{a}} / 2005$ e $\left.4^{\mathrm{a}} / 2010\right)$, dentre outros atores de igual importância. Desconsiderar este fator seria o mesmo que assumir que as instituições assistenciais, as Organizações Não Governamentais (ONGs) e outras instituições com iniciativa para mudar o contexto social não estão incluídas dentro das políticas públicas e não possuem participação relevante.

Dias (2012) acredita que o processo de elaboração de políticas públicas, anteriormente segmentado e linear, "se desenvolve de forma fluida, dinâmica e complexa". (DIAS, 2012, p. 44). Contudo, é bastante arriscada a generalização do conceito, ainda mais considerando a falta de continuidade das políticas públicas brasileiras. Caldas (2010a) contabilizou que "em 25 anos de governo de cinco presidentes (de 1985 a 2010), passaram pelo Ministério de C\&T nada menos do que 15 ministros, comprometendo a continuidade da política na área”. Naturalmente que a participação dos diversos atores sociais colaboram para que a elaboração dessas políticas sejam mais dinâmicas. Ainda sim, dinamismo não é uma das características marcantes de qualquer governo brasileiro. Há ainda muita burocracia quanto a normas legislativas que impedem essa fluidez. A complexidade realmente é uma constatação, considerando que o país tem culturas e infraestruturas regionais tão divergentes.

\section{O CICLO DE POLÍTICAS PÚBLICAS}

Dias (2012), Secchi (2012) têm visões diferentes quanto ao ciclo das políticas públicas. Foi utilizado um compilado de ambos, com o intuito de compreender melhor o processo. Primeiro o de cada um dos autores e na sequência, o adotado por este trabalho:

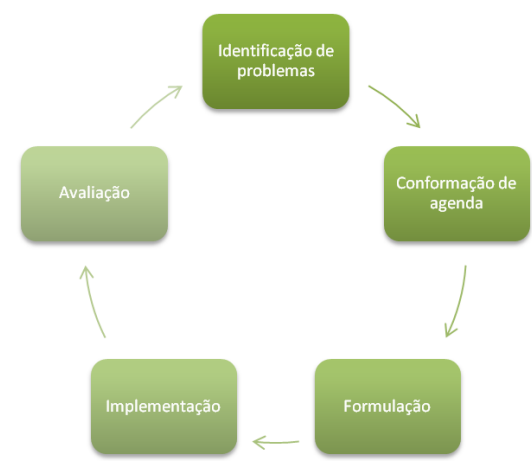

Figura 1: Ciclo de políticas públicas de (DIAS 2012

Fonte: Dias 2012 p. 45). Compilado dos autores Jones (1970); Dye (1976); Meny E Thoenig (1992); Frey (2000) e Roth Deubel (2006)

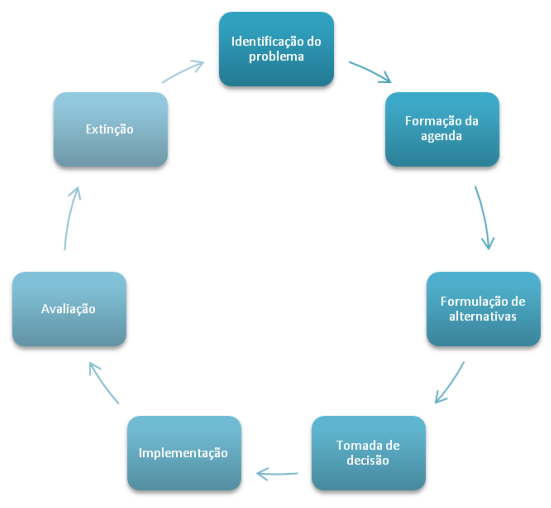

Figura 2: Ciclo de políticas públicas de Secchi 2012) Fonte: (SECCHI 2012 p. 33)

Explicando simplificadamente, a primeira fase, da identificação de problemas, como o próprio nome já 


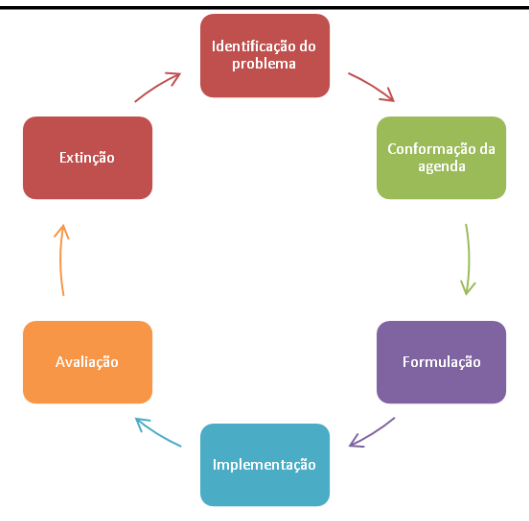

Figura 3: Ciclo de políticas públicas

Fonte: GARROTI, 2013. Adaptado a partir das ideias de (DIAS 2012] SECCHI 2012)

diz, reconhece as necessidades e as dificuldades de determinado grupo. Quando o problema é declarado público, é reconhecido de intervenção estatal e entra na agenda do governo. Essa é a segunda fase, a conformação de agenda. "A agenda é um conjunto de problemas ou temas entendidos como relevantes" (SECCHI, 2012, p. 36). Dias (2012) acredita que a tomada de decisão dos atores está inserida nesta fase, enquanto que Secchi (2012) insere essa particularidade depois da fase de formulação [de alternativas]. Ou seja, grupos com poder de influência já participam nesta fase, incluindo ações de acordo com seus interesses.

Se o problema já foi inserido na agenda de governo, é pertinente acreditar que a tomada de decisão acontece na sequência ou até mesmo antes disso, nas identificações dos problemas. Considerando tratar-se de uma fase intermediária e intrínseca ao processo, consta apenas como movimentação para as fases seguintes e, desta forma, não figura no modelo adotado por este trabalho como fase exclusiva.

A terceira fase é a da formulação. Neste momento, é quando as intenções da agenda tornam-se ações. Já a quarta fase é a fase da implementação, em que, após o planejamento das ações - que ocorreram na fase da formulação, a execução efetivamente acontece. Secchi (2012) afirma que "além de analisado, o momento da implementação deve ser gerenciado" (SECCHI 2012 p. 46), de forma que se verifique os resultados preliminares e se faça as devidas adequações.

Na quinta fase, a da avaliação, Secchi (2012) diz que pode ocorrer de três maneiras: ex-ante (antes), ex-post (após) e in itinere (durante, como uma espécie de monitoramento). Sugere que a avaliação possa ser realizada considerando alguns itens importantes:
Economicidade (utilização de recursos); eficiência econômica (recursos utilizados $\mathrm{X}$ produtividade); eficiência administrativa (conformação da execução a métodos preestabelecidos), eficácia (nível de alcance de metas ou objetivos preestabelecidos), equidade (homogeneidade de distribuição de benefícios (ou punições) entre os destinatários de uma política pública) [SECCHI 2012 p. 50)

Dias (2012) esclarece que "em particular no caso da política científica e tecnológica brasileira, é preciso destacar também o fato de não ter sido objeto de avaliação sistemática, tendência essa que pode ser constatada ao longo de sua trajetória" (DIAS, 2012, p. 50). Sem a prática da avaliação, torna-se impossível fazer melhorias. Desta forma, são testadas as mesmas fórmulas, experiências e políticas a cada quatro anos, com nomes diferentes, em lugar de aperfeiçoá-las, a partir de uma avaliação minuciosa de seu processo. A falta de continuidade nas políticas públicas brasileiras também dificulta qualquer avaliação, visto que as ações são geralmente realizadas todas no curto prazo, uma vez que mesmo idealizadas no longo prazo, são descontinuadas pelos governos posteriores.

Dias também cita Dagnino (2007), que acredita que, no Brasil e nos países latino-americanos, a avaliação das políticas de C\&T "é orientada por critérios de qualidade e relevância exógenos (gerados nos países centrais) e ex-post (geralmente cunhados com o objetivo de legitimar um curso de ação previamente adotado)". (DAGNINO apud DIAS 2012, p. 50). Daí é possível verificar que as avaliações não reconhecem as características brasileiras, de forma que exigem o que a infraestrutura do exterior pode oferecer. Parece bastante natural que essa postura resulte em erros grosseiros de avaliação - as atividades devem ser adaptadas ao local onde estão sendo inseridas, aos valores da cultura local, com os recursos disponíveis e tipo de pessoal empregado. E como já dito anteriormente, o método de avaliação brasileiro, quando existe, numa maioria, apenas reforça o lado positivo da política pública, de forma que a avaliação seja utilizada para manter o mesmo governo no poder por mais quatro anos.

A sexta fase, da extinção, somente Secchi (2012) insere no seu esquema. Incluímos neste trabalho porque é uma das fases que acontece com frequência dentro das políticas públicas brasileiras. Secchi descreve que uma política pública é extinta "quando o problema que originou a política é percebido como resolvido; os programas, as leis ou as ações que ativavam a política pública são percebidos como ineficazes; o problema, embora resolvido, perdeu progressivamente importância e saiu das agendas políticas e formais". (SECCHI, 2012, p. 
53)

\section{HISTÓRICO - A C\&T NO BRASIL A PARTIR DOS ANOS 80}

O Brasil começa efetivamente uma política científica em meados do século XX, entre os anos 30 e 40 . Marcos importantes foram a criação da Universidade de São Paulo (USP) em 1934, da Sociedade Brasileira para o Progresso da Ciência (SBPC) em 1948, Conselho Nacional de Desenvolvimento Científico e Tecnológico (CNPq) e Coordenação de Aperfeiçoamento de Pessoal de Nível Superior (Capes) em 1951 e, no estado de São Paulo, da Fundação de Amparo à Pesquisa do Estado de São Paulo (Fapesp) em 1960. O golpe é instituído pouco tempo depois, em 1964, e a ditadura militar durou por praticamente 20 anos.

Os anos 80 no Brasil foram caracterizados pelo fim da ditadura militar e pelo movimento das Diretas Já, exigência popular concretizada somente em 1989, depois das eleições indiretas de 1985 que elegeram Tancredo Neves. Até então, a pasta de Ciência e Tecnologia não tinha estatura de Ministério. Era uma Secretaria vinculada à presidência da República. Com a morte de Tancredo, assumiu a presidência seu vice, José Sarney que, por meio de um decreto de 15 de março de 1985, criou o Ministério de Ciência e Tecnologia (MCT), tendo Renato Archer como primeiro ministro da área.

Portanto, enquanto os países europeus pensavam em políticas públicas de popularização da ciência já nos anos 90, o Brasil passava por outros momentos econômicos e democráticos, que inspiravam políticas públicas em outras áreas.

As primeiras eleições diretas aconteceram em 1990, quando Fernando Collor assumiu o poder. O governo Collor abriu os mercados para produtos importados (e dificultou a vida dos empresários, que não estavam preparados para concorrências tão injustas) e iniciou o processo de privatização de estatais. Para combater a inflação, o governo optou pelo congelamento de preços e salários, bloqueios de contas-correntes e poupanças e demissão de funcionários públicos. “(...) O imperativo da estabilização impôs à política científica e tecnológica uma importância secundária." (DIAS 2012, p. 126). Os planos não tiveram resultado satisfatório, causando recessão e insatisfação dos eleitores. Após escândalos de corrupção no governo, houve o impeachment do presidente em 1992. Assume o vice, Itamar Franco, até novas eleições, quando outro Fernando assume. "As décadas de 1980 e 1990 foram notadamente marcadas pelo desmonte das estruturas estatais construídas ao longo das décadas anteriores". (DIAS, 2012, p.130)
As transformações mais evidentes pelas quais passou a política científica e tecnológica brasileira a partir de 1985 - em especial, naquilo que se refere à captura da agenda de pesquisa e da própria PCT por atores particulares foram particularmente perceptíveis a partir da década de 1990. (DIAS 2012 p. 131)

O governo de Fernando Henrique Cardoso (FHC), que durou dois mandatos, instituiu um novo plano econômico, mudando a moeda brasileira para o real e estabilizando a economia, vencendo a inflação. Ainda manteve a política de Collor em realizar mais privatizações. O segundo mandato de FHC apresentou um período de crises sucessivas, inclusive no setor energético, de forma que os quatro anos foram, de certa forma, um gerenciamento das dificuldades econômicas e políticas. Em 2001, na $2^{\text {a }}$ Conferência Nacional de C\&T, no entanto, no final do mandato de FHC (que durou até 2002), a comunidade acadêmica já apontava a necessidade de maior investimento em pesquisa, divulgação, educação científica e popularização do conhecimento.

Já o primeiro governo Lula, após os mandatos de FHC, foi cercado de expectativas quanto à mudança partidária do maior cargo político nacional.

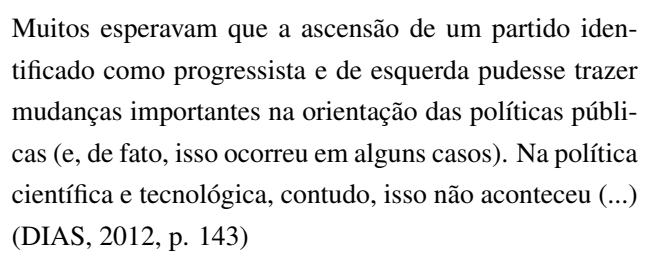

Apesar de ambos os governos Lula apresentarem políticas com o intuito de inclusão social, de transformar Ciência, Tecnologia e Inovação em instrumentos do desenvolvimento nacional ou servirem de acesso da população mais pobre aos benefícios do progresso, o resultado não foi condizente com o plano inicial:

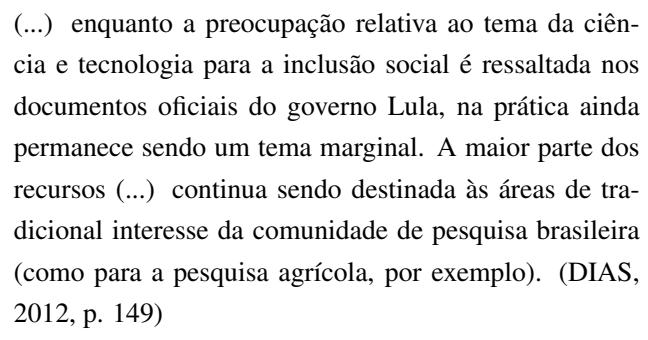

No entanto, foi a partir do governo Lula, que foi criada a Secretaria Nacional de Ciência e Tecnologia para a Inclusão Social (Secis) em 2003 e dentro dela, o Departamento de Difusão e Popularização da Ciência. O Brasil, muito atrasado no que tange às políticas de popularização científica com relação aos demais países, 
finalmente consegue, a partir dos anos 2000, discutir de forma ampla uma política de ciência e tecnologia, com o reconhecimento de seu papel no desenvolvimento do país, bem como da importância da popularização da ciência como parte do desenvolvimento social.

As atividades da Secis são bastante abrangentes e seguem duas frentes: "Difusão e popularização da C\&T" e "Tecnologia para o desenvolvimento social". "É preciso salientar que essa diversidade de temas sobre os quais a Secis atua acaba prejudicando a própria consecução de seu propósito maior: estimular a produção e difusão de conhecimento para alavancar o desenvolvimento social" (DIAS, 2012, p. 167). Os desafios do setor são bem grandes e precisariam de ações articuladas com outros ministérios e secretarias para serem desenvolvidos de forma mais efetiva. Contudo, esses desafios são difíceis de serem alcançados, já que os recursos disponibilizados para o setor há muitos anos mantém a média de apenas $1 \%$ do Produto Interno Bruto (PIB), apesar de reiteradas promessas de se chegar a $2 \%$, conforme é possível observar no gráfico a seguir:

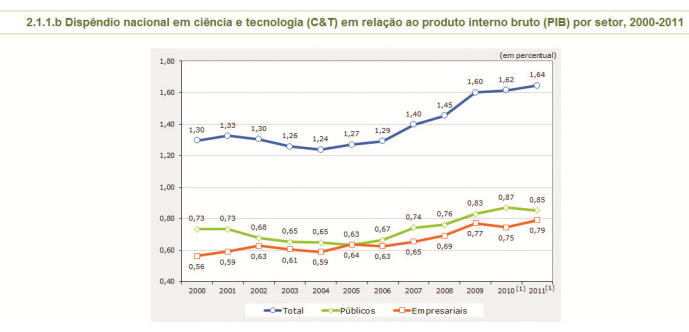

Figura 4: Dispêndio nacional em ciência e tecnologia (C\&T) em relação ao Produto Interno Bruto (PIB) (2000-2011)

Fonte: Ministério de Ciência, Tecnologia e Inovação

(MCTI)/Instituto Brasileiro de Geografia e Estatística (IBGE). Disponível em

urlhttp://www.mcti.gov.br/index.php/content/view/308845.html, acessado em 4/3/2013, às 19 h18

As ações continuam, portanto, bastante limitadas, também porque não houve aumento de investimento no setor. Não há como exigir mudanças enquanto não houver reavaliação orçamentária.

Segundo o Livro Branco da $2^{\text {a }}$ Conferência Nacional de Ciência e Tecnologia que aconteceu em 2001, não basta apenas o investimento público, é necessário também o investimento privado:

A dimensão do desafio que nos é lançado pelo futuro foi ilustrada de maneira emblemática no Livro Branco. Para alcançarmos, daqui a dez anos [2012], o patamar de $2 \%$ do [Produto Interno Bruto] PIB em investimentos em [Pesquisa e Desenvolvimento] P\&D, num hori- zonte de crescimento médio de PIB da ordem de $4 \%$ ano ano, assim como a aplicação da participação das empresas para o menor patamar hoje vigente nos países desenvolvidos, os investimentos em $\mathrm{P} \& \mathrm{D}$ devem crescer à taxa média anual de quase $12 \%$. Isso significa que, de um lado, o setor público - federal e estadual - necessitará elevar os investimentos à taxa média anual de cerca de $7 \%$; de outro lado, será necessário ao setor privado incrementar seus investimentos, de forma correspondente, da ordem de $15 \%$, aproximando-se do padrão dos países da [Organização para a Cooperação e Desenvolvimento Econômico] OCDE (BRASIL, 2002:xiii).

O crescimento do país não depende única e exclusivamente do Estado. Algumas iniciativas governamentais, dos últimos anos, como a Lei de Inovação de 2004 e o apoio à criação de Parques Tecnológicos em todo o Brasil, têm aproximado a iniciativa privada da área de Ciência, Tecnologia e Inovação (CT\&I). Entretanto, ainda há muito a fazer para ampliar o número de patentes do Brasil, e ainda que o país cresça na produção de artigos científicos, continua patinando para converter ciência em tecnologia e inovação para o setor produtivo.

\section{AS TRANSFORMAÇÕES QUE AS POLÍTI- CAS PÚBLICAS PODEM OFERECER}

Conforme já explanado anteriormente, as políticas públicas são a tentativa de corrigir ou transformar os problemas sociais. É um processo bastante complexo, que interliga diversos atores e interesses, contextos culturais e econômicos. Há ainda muita dificuldade de planejamento, avaliações equivocadas, estruturas deficientes. E toda essa conjuntura dificulta as transformações, que acontecem de forma gradativa, porém muito lenta.

Há de se considerar também o contexto histórico, que influencia há séculos a atual posição econômica dos países, desde o período da colonização de alguns territórios. No mundo capitalista, há espaço apenas para concorrência. É preciso, portanto, ver o crescimento das políticas públicas por meio deste olhar particular. Ainda que se perceba que as grandes crises só são superadas no regime colaborativo, este comportamento é pouco utilizado na atualidade. Menezes (2005) tem a visão agregadora de que "quem se sente parte desta aventura, há de também estar menos conformado com a barbárie da guerra e com a perversidade da exclusão, pois ser solidário implica fazer parte, pertencer" (MENEZES, 2005, p. 159).

Pavan (2005) lembra que passamos pela terceira revolução industrial, em que um "limitado número de nações destaca-se por sua base tecnológica moderna e pela utilização de tecnologias de ponta, que estão alte- 
rando o perfil de produção na indústria, na agricultura, no comércio e em outros serviços" (PAVAN, 2005, p. 93). Esclarece que não há futuro brilhante para as nações que se apoiam demasiadamente no fornecimento de matérias-primas e em produtos que resultam de trabalho pouco qualificado. Ainda:

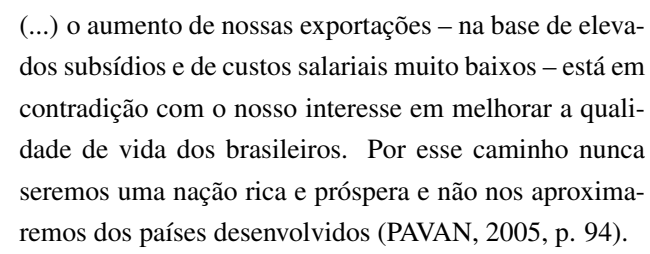

Há outro ponto importante que o autor chama a atenção. Reclama-se tanto da qualificação do empregado, que quando o mesmo se qualifica, o mercado paga baixos salários, dificultando o giro da economia. No entanto, após um padrão de consumo preestabelecido, é difícil desestruturá-lo e modificá-lo de acordo com o momento econômico. A Europa passa há vários anos por uma recessão da qual ainda não conseguiu se recompor. A população economicamente ativa é cada vez menor, graças ao aumento da qualidade de vida e essas características devem ser levadas em consideração na elaboração de políticas públicas condizentes com a região e com os habitantes que nela habitam.

Quanto ao conhecimento tecnológico, o Brasil se destaca em informática, biotecnologia e pesquisa agrícola. São áreas que o Brasil é pioneiro e referência. É possível, portanto, desenvolver as outras áreas - e, para isso, seria necessário exigir das lideranças ações nesse sentido.

Segundo Barros (2005), o desenvolvimento da CT\&I tem seu preço determinado pelo mercado. O barateamento de tecnologias leva tempo e utiliza-se de novas pesquisas para substituir as peças mais caras. "Assim, a abertura de novos mercados é fundamental para garantir o desenvolvimento de novas tecnologias e a manutenção do fluxo de capital". (BARROS, 2005, p. 112). Ainda vivemos num mundo mercantilista que não tem paciência de esperar pelos frutos. Os resultados precisam vir em até quatro anos, a cada mandato político, do contrário não se considera que os resultados tenham vindo da gestão anterior e sim da gestão atual. Essa pressa e a falta de ética no desenvolvimento da ciência causam prejuízos ambientais, destruição das culturas e aumento da exclusão social.

Barros (2005) garante que "não se poderá, de forma alguma, pensar no futuro da humanidade em termos de um grupo de interesses. Nesse quadro, a divulgação da ciência assume um papel político da mais alta relevância, pois será a partir da pesquisa científica e de sua divulgação à sociedade, que se poderá saber os limites da aplicação de determinada descoberta" (BARROS, 2005, p. 117). Essa sentença contempla vários itens importantes, que são:

- Considerar posturas e opiniões de diferentes grupos sociais e culturais. Quando se considera apenas um grupo de interesses, se atrasa o desenvolvimento da ciência, uma vez que apenas um grupo decide o que deve ser pesquisado;

- Toda pesquisa científica pondera limites de aplicação. A ética é fundamental, de forma atrelada à ciência, de modo que devem se tornar inseparáveis;

- A divulgação científica pode trazer esperanças, tanto verdadeiras quanto falsas. Há uma responsabilidade importante nessa divulgação. A crença de que determinada área está próxima de encontrar a cura de uma doença; ou a melhoria da tecnologia agrícola, que acelera a produção de determinada cultura, modifica consideravelmente a vida de milhares de brasileiros. Por isso a divulgação deve ser cuidadosa.

\section{CONCLUSÕES}

É possível notar que as políticas públicas científicas possuem um desenvolvimento diferenciado e dependem muito do tipo de liderança, infraestrutura disponível, formas de gerenciamento e momento político, dentre muitos outros fatores. A mesma política pública pode ser bem-sucedida em uma região e mal-sucedida em outra. Pode não ter dado resultado satisfatório no passado e ser extremamente eficiente nos dias atuais. A política pública de ciência deve ser pensada levando em consideração essas nuances, características e detalhes. Caldas (2010b) defende que é necessário familiarizar as coletividades sobre os processos de elaboração de políticas públicas de CT\&I, seus atores e detratores quando questiona:

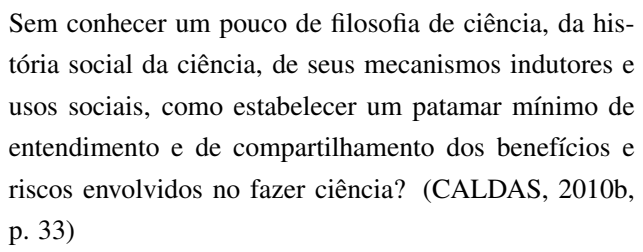

Para participar das mudanças, é necessário que a sociedade compreenda as dificuldades e seja ativa na proposta e no desenvolvimento destas políticas.

Como decidir onde investir? Como cientista, pesquisador e divulgador, Pavan (2005) propõe - de modo 
bastante politizado - "que os investimentos em C\&T só se justificam quando apresentam consequências para o desenvolvimento do país, ou pelo menos no desenvolvimento científico básico" (PAVAN, 2005, p. 95). Desde que resulte em benefício para a própria sociedade, $\mathrm{o}$ investimento se justifica.

Contudo, não é possível mudar a realidade da CT\&I sem mudar a conjuntura dos outros problemas sociais. Como garante o autor:

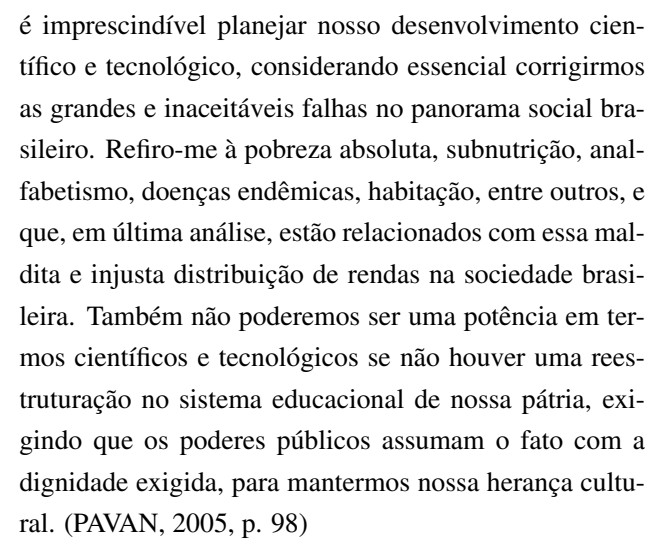

O esforço, portanto, deve ser coletivo e bastante intenso. Não há desenvolvimento em apenas uma área, é necessário esforço em todos os sentidos e para isso, todos devem trabalhar em conjunto.

\section{AGRADECIMENTOS}

Este trabalho foi financiado pela Fundação de Amparo à Pesquisa do Estado de São Paulo - Fapesp.

\section{REFERÊNCIAS}

BARROS, H. L. d. Um novo papel da divulgação da ciência: rumo a um contrato tecnológico. Educação Científica e desenvolvimento: o que pensam os cientistas., Instituto Sangari, p. 112-117, 2005. Instituto Sangari.

CALDAS, G. Políticas públicas de c\&ti na agenda social? Com Ciência Ambiental, p. 94-97, junho 2010a.

Divulgação científica e relações de poder. Informação e Informação, v. 15, n. esp, p. 31-42, 2010 b.

DAGNINO, R. Ciência e tecnologia no Brasil: o processo decisório e a comunidade de pesquisa. : Campinas: Editora Unicamp, 2007.

DEMO, P. Pesquisa e informação qualitativa: Aportes Metodológicos. Campinas: Papirus, 2001.
DIAS, R. de B. Sessenta anos de política científica e tecnológica no Brasil. Campinas: Editora da Unicamp, 2012.

MENEZES, L. C. d. Cultura científica na sociedade pós-industrial. Educação Científica e desenvolvimento: o que pensam os cientistas, Instituto Sangari, Brasília: UNESCO, p. 159, 2005.

PAVAN, C. Investimento, ciência e educação. Educação Científica e Desenvolvimento: o que pensam os cientistas, Instituto Sangari, Brasília: UNESCO, p. 94-98, 2005.

SANTAELLA, L. Comunicação e pesquisa: projetos para mestrado e doutorado. : São Paulo: Hacker Editores, 2001.

SECCHI, L. Políticas públicas: conceitos, esquemas de análise, casos práticos. São Paulo: Cengage Learning, 2012. 